\title{
Learners in Transition Between Contexts
}

\author{
Tamsin Meaney \\ Malmö University, Sweden \\ Troels Lange \\ Malmö University, Sweden
}

\begin{abstract}
In this chapter, we explore, from a social justice perspective, conceptions of learners in transition between contexts and evaluate pedagogical practices that have been advocated for such learners. Learning occurs as learners reflect on their transition between contexts, particularly when there are differences in what content knowledge is valued, the relationships between participants and how activities are undertaken. From this perspective, productive pedagogical practices for learners in transition are those that build and sustain relationships between learners and mathematics and between learners and others, including those outside the classroom. We look specifically at examples of pedagogical practices that draw on ethnomathematics and critical mathematics education for their inspiration.
\end{abstract}

Keywords: critical mathematics education, disadvantage in mathematics, ethnomathematics, mathematics learners' perspectives, modes of belonging, politics of knowledge, social justice and mathematics, transitions in mathematics

Transitioning between contexts, such as home and school, can be a fairly minor issue for learners if they perceive similarities in what knowledge is valued and how learners and others should interact together and with the mathematical content. However, for other learners who perceive the contexts as being very different, the transitioning process can limit the possibilities for their future. This is because transitioning between contexts affects not just what knowledge is valued, and thus learnt, but also learners' processes of becoming. In this chapter, we describe how learning is connected to transitioning between contexts, before discussing different positions on social justice in mathematics education. In so doing, we identify two pedagogical approaches, ethnomathematics and critical mathematics education, to analyze using Wenger's (1998) three modes of belonging. Using learners' opinions, we identify the features of these approaches that support learners to broaden horizons of possibilities for their futures.

Adjusting to new contexts always involves learning. The degree of adjustment varies depending on the similarities or differences between contexts. Nevertheless, even when contexts have a connection to mathematical knowledge, learning may not include gaining school mathematical outcomes. de Abreu, Bishop and Presmeg (2002) saw the transitioning process as being part of a dynamic relationship between the learner and the contexts being transitioned. Contexts act as mediators between what is structurally possible, through schooling for example, and what actually happens, such as learning. Thus, we see contexts as the enactment of systems of knowledge within social practices, whose elements Fairclough (2003) described as: (a) action and interaction; (b) social relations; (c) persons (with beliefs, attitudes, histories, etc.); (d) the material world; and (e) discourse.

The following is an example of how social practices contribute to actual events:

Classroom teaching articulates together particular ways of using language (on part of both teachers and learners) with the social relation of the classroom, the structuring use of the classroom as a physical 
space, and so forth. ... Social events are casually shaped by (networks of) social practices-social practices define particular ways of acting, and although actual events may more or less diverge from these definitions and expectations (because they cut across different social practices, and because of the causal powers of social agents), they are still partly shaped by them. (Fairclough, 2003, p. 25)

Thus, contexts are not just physical settings, but include the valuing of knowledge, the typical distribution of power within relationships that interact around that knowledge and the sorts of interactions that are expected to occur between participants and with that knowledge. As such, contexts can be considered systems of knowledge enacted in social practices.

Transitions between contexts have been referred to as boundary crossings (Crafter \& de Abreu, 2011). Lipka, Yanez, Andrew-Ihrke and Adam (2009) described boundary work as education across cultures which "requires bridges between elders and schooling" (p. 267). Bishop (2004) used Gee's (1996) description of "borderland discourses" to describe the differences between home and school mathematical practices. An alternative is to consider transitions in relationship to a change in horizons of learners' possibilities for their futures. Gadamer (1996) stated "the horizon is the range that includes everything that can be seen from a particular vantage point. ... we can speak of narrowness of horizon, of the possible expansion of horizon, of the opening of horizon and so forth" (p. 302).

For example, when transitioning between contexts involves the loss of connections with the home, this can be considered a narrowing of learners' horizons of possibilities for their futures. An Indigenous group "may well recognize that schooling provides the skills necessary to survive in a technological world, but it will also blame the school for alienating students from their home culture, whether deliberately or unintentionally" (Cantoni, 1991, p. 34).

At times, transitions can be one-way, so it is not possible to return to the original contextthe horizon in one direction closes while another expands. For example, Gorgorió and Planas (2003) stated, "[w]hen referring to the schooling of immigrant children, transition processes may be viewed as the gradual adaptation to societal expectations" (p. 3). On the other hand, transitions between home and school occur on a regular basis and although learning may result in a reinterpretation of each context, the knowledge valued in one context would not be replaced by that from the other context. de Abreu et al. (2002) labelled these as collateral transitions. In these situations, learners have to learn how to juggle the discontinuities between the different social practices.

We understand the construct of transition not as a moment of change but as the experience of changing, of living discontinuities between cultures; in particular, discontinuities between different school cultures, and different mathematics classroom cultures, and between how the home and school culture understand, value and use mathematics. Transitions include the processes of developing both individual and social identities while coping with new social and cultural experiences. (Gorgorió \& Planas, 2005, p. 93)

Transitioning is dynamic and never-ending. For example, César (2007) described a student in Portugal who is first seen as being disruptive. When a new teacher provided him with different activities, he began to engage in learning mathematics. He then had to re-negotiate his role with his Cape Verde friends and community who had come to expect that he would have a leadership role in disrupting the mathematics class. Transitioning into new contexts and between contexts results in learning. New understandings can be used to reflect on the same contexts, but in new ways, thus contributing to transitioning being an ongoing process. Learning is more than a passive interpretation of the world, as it can result in changes to the contexts themselves (Diversity in Mathematics Education Center for Learning and Teaching [DiME], 2007) and to the horizons of future possibilities.

For Radford (2008), learning involved becoming progressively conversant with the collectively and culturally constituted forms of reflection. Learning is "not just about knowing something but also about becoming someone" (Radford, 2008, p. 215). In this way, the object of learning is not only within the awareness of the learner, but the learner him/herself is part of what 
is to be appropriated in the learning process. Similarly, Brown (2009) stated "a person's becoming occurs through engagement in the ways of knowing, doing and valuing of a particular social group, for example, philosophers, mathematicians, lawyers, gang-members, etc" (p. 172). Thus, learning embeds the individual within the historically-developed societal context. The appropriation of forms of reflection happens in the entangled relationship between the individual, the collective and forms of practice, mediated through artefacts. Reflection produces conceptions of contexts while, simultaneously, interactions within and between contexts support the appropriation of the socially-constructed and culturally-constituted forms of reflection.

When learners transition between two contexts that are very similar, the need for adjustments may not be large. For other learners, such as Indigenous students, learning mathematics may involve querying their perceptions of what knowledge is and how it is gained (see for example Barta \& Brenner, 2009). It is likely that many Indigenous students would agree with Gorgorió and Planas (2005) that "the common understanding of the [mathematics] student is still 'monolingual', belonging to the dominant culture, and having middle class social attitudes" (p. 92). Consequently, when participants construct relationships in the mathematics classroom that position learners as being different from "typical" mathematics learners, then transitioning is likely to be difficult. Similarly, when learners transition into outside-school contexts where school mathematics is not valued, then the transitioning also can be problematic. This can occur when immigrant children have to do homework that their parents consider to have limited mathematical value (Civil, 2008). In these cases, learners are forced into reflecting on the differences, resulting in a different kind of learning than that which probably was intended by, for example, the teachers.

Although the transitioning process is never completed, it continually produces outcomes. As a result of reflecting on their learning experiences, learners may decide to adapt so they more closely resemble what they consider to be "typical" mathematics learners, or they may choose not to engage with mathematics, or they may accommodate to these new forms of reflection by doing something in between. An example of this would be when learners do not perceive that transferring knowledge across contexts is valuable. For example, Nunes, Schliemann, and Carraher (1993) described how children who operated as street vendors were able to do complex calculations as part of their jobs but could not relate these calculations to what they were required to do in mathematics classrooms. Similarly, Brenner (1998) found that first-grade children recognized that the prices given for textbook items did not reflect the money exchanges that they engaged in outside of school. For both sets of learners, an outcome was that mathematics was compartmentalized so that only one type of mathematics could be used in each context. Transitioning can result in a range of outcomes depending on the learners' reflections.

Skovsmose (2005) saw learners' perceptions of their situation as being pivotal to the sort of learning in which they engaged. Learners' backgrounds as well as their foregrounds, that is, perceived opportunities for their futures, form their dispositions to learn. Like Radford's descriptions of reflections, these perceptions are not individually formed but are collectively and culturally situated. When learners transition between contexts, different foregrounds and backgrounds come to their attention. As a result, dispositions to learn can be contradictory.

\footnotetext{
Intentions of learning emerge out of dispositions. Dispositions are concerned with "background" as well as "foreground" and are revealed when the learner produces, creates or decides his or her intention. A situation which could raise intentions for learning does not automatically belong to the background of the student having to do with his or her situation and social or cultural heritage. It is just as much to do with the students' possibilities but the possibilities as the student perceives them. The decision of the learner to act or learn therefore has a role to play when conditions for learning are created. The student has to be involved in the learning - should want to learn - if the learning activity is to become learning as action. Furthermore, the learning has to be performed by the learner if it is to include reflections and a critical awareness. (Vithal \& Skovsmose, 1997, p. 147)
}

If the learning situation supports the active involvement of learners, intentions for learning are 
formed and the resulting learning process is one of action (Alrø \& Skovsmose, 2002). When learners identify with the teacher's suggested outcomes of the learning activity, then joint ownership and shared perspectives between the teacher and learners develop. When learners' intentions differ, then so will the outcomes from learning.

In this chapter, we investigate pedagogical approaches, advocated for learners whose learning seems to involve a complex transition process. Reflection on the intertwining of backgrounds and foregrounds will affect learners' decisions to engage and to a broadening or narrowing of their horizons of possibilities for their future. Consequently, we consider the impact of transitioning between contexts, in which mathematical knowledge and ways of interacting around it are perceived differently, to be an issue of social justice.

\section{Situating Pedagogical Approaches as an Issue of Social Justice}

Investigations of social justice within mathematics education have focussed on the learnerteacher relationship and the pedagogical practices used in mathematics classrooms (Atweh \& Brady, 2009). However, Fairclough's (2003) description of learning suggests that as one part of the entangled relationships that contributes to learning, pedagogical practices, as social practices, involve the valuing by participants of certain systems of knowledge. Learners' dispositions will be affected by relationships with mathematics held by other participants, such as teachers, students, and families. Relationships are not formed solely within an individual classroom but mirror the wider societal valuations of who and what is seen as important.

It is through this process of drawing on the resources of the various discourses available within a given classroom that individuals construct their identities as teachers and students of mathematics, positioning themselves in relation to the mathematical and nonmathematical activity within the classroom and in relation to the other participants in the classroom and accounting - to themselves and to others-for the nature of their own participation. The privileged official discourses provide what may be constructed "natural" positions for teachers and students, although individuals may resist this discourse. (Morgan, 2009, p. 98)

Curriculum, representing official discourse, identifies what should be learnt and sometimes how it should be learnt, constrains teachers' abilities to implement pedagogical practices.

Table 1, from Willis (1998), summarizes four social justice approaches within mathematics education and illustrates how these are likely to channel teachers and learners into forming different kinds of relationships with each other and with mathematical knowledge. Yet, the table also illustrates that it is difficult to discuss perspectives on social justice in ways that do not position some groups as always being outside of the curriculum. This is especially the case in Perspectives 1 and 2, but even in Perspectives 3 and 4 there is an implicit comparison between "others" and the "norm." In the final perspective, the educational task is described as to "help children develop different views of who does mathematics and what it means to be good at it, to understand how they are positioned by mathematics and how to use it in the interests of social justice" (p. 15). The word "different" indicates that the current norm does not do this. It is implicit that those who are affected most by social justice inequities and so have the more complex transitioning to do, are the ones who need this alternative curriculum.

In considering learners transitioning between contexts, all the perspectives acknowledge that there might be differences in how knowledge is valued between home and school contexts. However, the assumption is that the transitioning process is one way-into classrooms. Perspective 4 is the only one that seems to recognize that learners also transition out of school contexts and that the curriculum may have a role in easing that transitioning process. 
Table 1

Different Perspectives on the Relationship Between Disadvantage, the Mathematics Curriculum and Social Justice (from Willis, 1998, p. 15)

\begin{tabular}{|c|c|c|c|c|}
\hline & $\begin{array}{c}\text { Perspective } 1 \\
\text { Remedial }\end{array}$ & $\begin{array}{c}\text { Perspective 2: } \\
\text { Non- } \\
\text { Discriminatory }\end{array}$ & $\begin{array}{l}\text { Perspective } 3: \\
\text { Inclusive }\end{array}$ & $\begin{array}{c}\text { Perspective 4: } \\
\text { Socially Critical }\end{array}$ \\
\hline $\begin{array}{l}\text { The } \\
\text { mathematics } \\
\text { curriculum is } \\
\text {... }\end{array}$ & $\begin{array}{l}\text { a given, } \\
\text { including } \\
\text { what is to be } \\
\text { learnt, how it } \\
\text { is taught and } \\
\text { how it is } \\
\text { assessed. }\end{array}$ & $\begin{array}{l}\text { a given with } \\
\text { respect to what } \\
\text { is to be learnt, } \\
\text { but how it is } \\
\text { taught and how } \\
\text { it is assessed are } \\
\text { not. }\end{array}$ & $\begin{array}{l}\text { a selection from } \\
\text { all possible } \\
\text { curricula and } \\
\text { therefore neither } \\
\text { given nor } \\
\text { unchangeable. }\end{array}$ & $\begin{array}{l}\text { actively implicated in } \\
\text { producing and reproducing } \\
\text { social inequality being one of } \\
\text { the ways in which dominant } \\
\text { cultural values and group } \\
\text { interests are maintained. }\end{array}$ \\
\hline $\begin{array}{l}\text { The problem } \\
\text { of "disad- } \\
\text { vantage" lies } \\
\text { with ... }\end{array}$ & $\begin{array}{l}\text { the children } \\
\text { some of } \\
\text { whom by } \\
\text { virtue of their } \\
\text { race ethnicity, } \\
\text { gender, social } \\
\text { class or } \\
\text { disability are } \\
\text { less well } \\
\text { prepared than } \\
\text { others to get } \\
\text { the full } \\
\text { benefits of the } \\
\text { curriculum. }\end{array}$ & $\begin{array}{l}\text { pedagogy and } \\
\text { assessment } \\
\text { practices which } \\
\text { favour or relate } \\
\text { to the } \\
\text { experiences, } \\
\text { interests, and } \\
\text { cultural practices } \\
\text { of some social } \\
\text { groupings of } \\
\text { children more } \\
\text { than others. }\end{array}$ & $\begin{array}{l}\text { curriculum } \\
\text { content and } \\
\text { sequence which } \\
\text { reflect the } \\
\text { values, priorities } \\
\text { and lifestyles of } \\
\text { the dominant } \\
\text { culture and } \\
\text { match the } \\
\text { typical } \\
\text { developmental } \\
\text { sequences } \\
\text { associated with } \\
\text { their children. }\end{array}$ & $\begin{array}{l}\text { the way the mathematics } \\
\text { learner is constructed through } \\
\text { the curriculum and the way } \\
\text { mathematics is used inside } \\
\text { and outside schools to } \\
\text { support and produce } \\
\text { privilege. }\end{array}$ \\
\hline $\begin{array}{l}\text { The solution } \\
\text { is to ... }\end{array}$ & $\begin{array}{l}\text { help such } \\
\text { children } \\
\text { become better } \\
\text { prepared for } \\
\text { school } \\
\text { mathematics. }\end{array}$ & $\begin{array}{l}\text { change pedagogy } \\
\text { and assessment } \\
\text { practices to } \\
\text { ensure children } \\
\text { have real equity } \\
\text { of access both to } \\
\text { the mathematics } \\
\text { and to the means } \\
\text { of demonstrating } \\
\text { their learning. }\end{array}$ & $\begin{array}{l}\text { rethink who } \\
\text { "the typical } \\
\text { child" is for } \\
\text { whom our } \\
\text { curriculum is } \\
\text { developed, what } \\
\text { school } \\
\text { mathematics is, } \\
\text { what should be } \\
\text { learned, by } \\
\text { whom and } \\
\text { when. }\end{array}$ & $\begin{array}{l}\text { challenge and modify the } \\
\text { hegemony of mathematics } \\
\text { and use mathematics } \\
\text { explicitly in the services of } \\
\text { social justice. }\end{array}$ \\
\hline $\begin{array}{l}\text { The } \\
\text { educational } \\
\text { task is to ... }\end{array}$ & $\begin{array}{l}\text { provide } \\
\text { children with } \\
\text { the missing } \\
\text { skills, } \\
\text { experiences, } \\
\text { knowledge, } \\
\text { attitudes or } \\
\text { motivations. }\end{array}$ & $\begin{array}{l}\text { draw upon and } \\
\text { extend children's } \\
\text { experiences, } \\
\text { provide a } \\
\text { supportive } \\
\text { learning } \\
\text { environment and } \\
\text { more valid } \\
\text { assessment } \\
\text { opportunities. }\end{array}$ & $\begin{array}{l}\text { provide } \\
\text { children with } \\
\text { curricula } \\
\text { which better } \\
\text { acknowledge, } \\
\text { accommodate, } \\
\text { value and } \\
\text { reflect their } \\
\text { own and their } \\
\text { social groups' } \\
\text { experiences, } \\
\text { interests and } \\
\text { needs. }\end{array}$ & $\begin{array}{l}\text { help children develop different } \\
\text { views of who does mathematics } \\
\text { and what it means to be good at it, } \\
\text { to understand how they are } \\
\text { positioned by mathematics and } \\
\text { how to use it in the interests of } \\
\text { social justice. }\end{array}$ \\
\hline
\end{tabular}


Focussing on pedagogical approaches readjusts the emphasis from the deviant performance of particular groups of learners, where the main outcome of an appropriate transitioning would be to have them perform similarly to "normal" students. Mathematics education has for a long time documented cases of learners who underachieve but research on pedagogical practices that produce more positive results have not been so prolific (Anthony \& Walshaw, 2007; Nasir \& Cobb, 2007). We choose to analyze learners' views on pedagogical approaches, ethnomathematics and critical mathematics education, because they had similarities with perspectives 3 and 4 . In these perspectives, the mathematics curriculum is considered to be changeable and there is an emphasis on learners using their mathematics knowledge from outside of school within the classroom. Vithal and Skovsmose (1997) stated:

\begin{abstract}
Whilst ethnomathematics seems to deal mainly with cultural and social issues, critical mathematics education has largely focused on social and political aspects. These perspectives are, of course, connected. We conceive of ethnomathematics and critical mathematics education as two important educational positions in the attempt to develop an "alternative" mathematics education which expresses social awareness and political responsibility. (p. 131)
\end{abstract}

These perspectives on the connections between social justice and mathematics curriculum provide information on the structure of the relationships that learners can forge with mathematics and other participants within mathematics classrooms.

Biddy (2009) interviewed a large number of primary school students in England about their mathematics classes. Many interviews indicated that these children did not like the relationships in which they were positioned within the classroom. Consequently, she suggested that "a definition of pedagogy needs to be founded in relationships or relationality" (p. 135). Pedagogy as relationships has two components; mutuality and being seen and valued. Mutuality meant that the learning of the group was more important than learning of an individual which was in contrast to their teachers' view of the importance of the individual. For the learners, being seen and valued involved their teacher listening to them and valuing their contributions. If this is not done, Presmeg (2002) suggested that "symbolic violence [will be] experienced by students in transition between contexts when their cultural capital is devalued by significant others" (p. 226). Mathematics curricula provide parts of the structures in which teachers operate, but it is how they interpret these structures that will affect the relationships that are forged both inside and outside the classroom around mathematical understandings.

As discussed in later sections, ethnomathematics or critical mathematics education do not provide details about the sorts of relationships that they should foster. Yet in accepting that learning is about becoming and thus more than gaining familiarity with knowledge and skills, then there is a need to understand learners' perspectives on the relationships that they form. In the next sections, we identify learners' perspectives on being involved in ethnomathematics and critical mathematics perspectives from previous research. We then discuss these pedagogical approaches using Wenger's (1998) three modes of belonging to investigate the relationships to which they contribute.

Our primary sources for relevant research have been conferences such as Mathematics Education in Society and the International Conferences on Ethnomathematics. From lists of papers, we identified authors working in the field and located related journal articles and book chapters. Nevertheless, we have not located all relevant material.

Each section begins with a description of the pedagogical approach and theoretical concerns about them. Then, learners' perceptions of the impact of these approaches are described. At times we have used learners' views as reported second-hand through quotations from teachers. Although not ideal, the paucity of research limited the available data. The final section analyzes students' perspectives using the modes of belonging, to illustrate what supported their transitioning between contexts. 


\section{Ethnomathematics}

Ethnomathematics began in the 1980s as "the study of mathematical ideas of non-literate people" (Ascher \& Ascher, 1986) but soon broadened to the mathematical practices of specific groups, whether they be carpenters (Masingila, 1994) or cardiovascular surgeons (Shockey, 2002). The mathematics used and developed by Western mathematicians is one kind of ethnomathematics (Borba, 1990), although academic mathematics has sociological implications that other kinds of mathematics do not have (Knijnik, Wanderer, \& Oliveira, 2005). D'Ambrosio (1992) described a research program in ethnomathematics as "the study of the generation, organisation, transmission, dissemination and the use of jargons, codes, styles of reasoning, practices, results and methods" (p. 1183).

An ethnomathematical research program can be traced to two complementary research agendas: to understand better the mathematical practices of different groups (Bishop, 2004), and to support the development of a more just and socially equitable society that deals with the economic and environmental problems facing the world (D'Ambrosio, 2010). The first arose from work from the 1960s and 1970s which showed that the development of mathematical understandings was culturally related (Wedege, 2010). The second came from concerns about the loss of human dignity through the continual conflicts that afflict the world and the need for mathematics and mathematics education to contribute to efforts for peace (D'Ambrosio, 2010).

Despite these worthwhile aims, ethnomathematics has not been without criticisms. For example, the valuing of a practice only if it can be labelled as Western mathematics has been questioned (Jablonka \& Gellert, 2010). Barton (2004) stated that although ethnomathematics provides opportunities to reconsider how aspects of Western mathematics are perceived, labelling cultural activities as "mathematics" was problematic unless certain conditions were met. He specified that " $[\mathrm{t}]$ he knowledge should be systematized, should be formalized and should relate to quantity, relationships, or space. It must also be sufficiently abstracted to be removable from its practice" (p. 23). These conditions enable practitioners to be able to discuss their ideas as mathematics. Similarly, Pais (2011) suggested that although learners may engage in a range of activities, it is not until these activities are recognized that they become mathematics. However, labelling of traditional activities as mathematics runs the risk that they are seen as having no intrinsic value, except as examples of a Western knowledge system (Roberts, 1997).

Yet, ethnomathematics "has obvious pedagogical implications" (D'Ambrosio, 2010, p. 9). In a description of the Math in Cultural Contexts project, developed in Alaska over several decades, Lipka et al. (2009) summarized many of the assumptions on which their ethnomathematical pedagogy is based:

The assumptions include that students will gain increased access to the math curriculum because they can identify with the curriculum and pedagogy on multiple levels, from familiar contexts to familiar knowledge, and that they will have multiple ways of engaging with the material. ... Further it is assumed that the inclusion of local knowledge, language and culture may well have a positive effect on students' identity that will be different from the typically reported process of schooling that marginalizes so many AI/AN (American Indian/Alaskan Native) students. (p. 266)

Researchers in other parts of the world acknowledge similar assumptions (see, e.g., Adam, 2003; Laridon, Mosimege, \& Mogari, 2005). However, the diversity of aims could result in their being in conflict, making it difficult to implement an ethnomathematical approach that supports students to transition between contexts and broaden their horizons of possibilities.

Vithal and Skovsmose (1997) suggested that, to South Africans, the aims of ethnomathematics closely resemble those of apartheid where perceptions of cultural differences were used to differentiate education opportunities. To overcome the likelihood that some learners' opportunities would be limited, they recommended that students' foregrounds should be considered when choosing mathematics activities. As well, by presenting an activity as representative of a culture, a teacher could gloss over differences within that culture (Vithal \& 
Skovsmose, 1997). Considerations of foregrounds and backgrounds into designing of mathematics activities has been discussed as the need for "permeability."

A serious commitment to encouraging children to use mathematics to contribute to the solution of problems drawn from everyday life (whether textually represented in texts and tests or actually experienced in their life outside school) will also need to increase the permeability of the boundary between children's everyday knowledge and experience and their more purely mathematical knowledge. (Cooper \& Harries, 2002, p. 21)

If permeability is achieved then learners are likely to transition between contexts more easily. Knijnik (1998) reported that in the mathematics education program in which she worked with the Landless People Movement of Brazil "the interrelations between popular knowledge and academic knowledge are qualified, allowing the adults, youths and children who participate in it to concurrently understand their own culture more profoundly, and also have access to contemporary scientific and technological production" (p. 188). This suggested that for these learners participating in activities allowed them to transition both into and out of formal mathematical contexts.

In regard to immigrant classrooms, there have been consistent calls for teachers to know their learners better and to base their teaching on everyday mathematics that learners bring to the classroom ( Civil \& Planas, 2010; de Abreu \& Gorgorió, 2007). Moreira (2007) suggested that the mathematics teacher should act as an ethnomathematical researcher. When ethnomathematical practices have been used in the classroom (Barta, 2002; Masingila, Davidenko, \& PrusWisniowska, 1996), the activities have tended to be those of adults rather than children. There are few examples of children's own activities being used (see Masingila, 1996; Presmeg, 1996). Carraher and Schliemann (2002) suggested that "there seems to be relatively little mathematical activity in children's out-of-school activities, and when it does come into play, it does not seem to call for a deep understanding of mathematical relations" (p. 150).

As well, Stillman and Balatti (2001) warned that the process of bringing cultural activities into the mathematics classroom potentially "divorces the cultural practices from their context and trivializes and fragments them from their real meaning in context" (p. 325). In Papua New Guinea, the curriculum was changed to support the use of traditional knowledge in the mathematics classroom. Esmonde and Saxe (2004) suggested that the support for using vernacular languages and Indigenous counting systems in community schools may revive the use of tok ples counting systems but only by altering its structure so that it resembled the Hindu-Arabic system. Paraide (2005) also warned of the difficulties in trying to make connections between another Papua New Guinean counting system and the Hindu-Arabic one. Thus, although incorporation of traditional counting practices would achieve some of the aims of an ethnomathematical approach, alteration of the traditional knowledge could lead to a narrowing of learners' perceptions about the value of that knowledge in the future.

Reconciling the differences in how knowledge is valued in different contexts is often left to teachers who can struggle to do this (de Abreu, 1993). For example, a Ghanaian teacher felt that she was not able to bring in the learners' outside school knowledge about sharing according to status because she saw it as being in conflict with the fraction knowledge that the curriculum required her to teach (Davis, Seah, \& Bishop, 2009). In the United States, Cahnmann and Remillard (2002) described how one teacher working in a low socio-economic area was able to make cultural connections for her students so that they would enjoy mathematics, but struggled to make the tasks mathematically challenging. Consequently, the learners had limited access to academic mathematics.

In the Funds of Knowledge project described by Civil (n.d.), teachers visited the homes of some of their learners to identify activities that then could be used in the classroom to support connections being made between school and out-of school mathematical knowledge systems. 
Overall the money module focused on children discussing social issues in relation to money (such as welfare, food stamps, buying a car, a house) in the third grade class and on researching topics such as "money, power, and politics" or "foreign currencies," in the fifth grade class. Hence, in this class, the main academic areas emphasized through this module were social studies, reading and writing. In the third grade class, mathematics was more present, for example through connections to children's literature that had money as the focus. But even with the third graders, I think that we only scratched the surface of the mathematics in a module around money. The very rich discussions in both classrooms showed the wealth of knowledge that these children had about everyday uses of money, budgeting, and what it means not to have enough money. Yet, in terms of our mathematical agenda, I did not feel we succeeded in exploring the potential in this module. (p. 7)

Later, working with a different teacher, a unit based on gardening seemed be more solidly grounded in mathematics, although at times the mathematics activities were contrived. Notwithstanding, the teacher drew on parents and researchers as resources rather than the learners, Civil (n.d.) suggested that the learners cared about their plants and this contributed to their being interested in the mathematics problems.

Although there are high expectations about using an ethnomathematics approach to ease the transition between school and out-of-school contexts, some mathematics educators have queried its potential. In the next section, we describe learners' views about being involved in ethnomathematics activities.

\section{Learners' Views on Ethnomathematical Approaches}

From the perspective of learners, incorporating cultural activities into the mathematics classroom was valuable. The reasons for this varied from finding the activities interesting, to seeing these activities in a new light. This supported learners to reflect not only on what they were learning but also on how they were learning, leading potentially to a broadening of their horizons for future possibilities. In reflecting on how they were learning, learners expressed a desire to be more involved in group work and to learn by doing, through working with artefacts.

Mosimege and Ismael (2004) reported on learners' enjoyment in mathematics lessons that were based around traditional African games.

The last sessions were very nice. The game practice was very nice. We used to play this game at home
without knowing what is essential in it. (pp. 132-133)
I liked the lessons, they very exciting because we were taught by doing... With this way of teaching you
can learn really (...) other teachers should also teach us in this way if there is a possibility. (p. 133)

In the first quotation, recognizing the game as mathematics seemed to make it more valuable for the learner. In a later article, Nkopodi and Mosimege (2009) commented on the need to ensure that the mathematics was visible and the games were not merely considered fun activities. However, as noted above, there is a risk that the inherent value of the game itself is lost and this could lead to a narrowing of horizons around traditional practices.

Getting students involved in ethnomathematics projects was considered to be a way of supporting learning. In Israel, a tenth-grade teacher in an Arab school worked with researchers to introduce a geometry unit based on traditional geometric designs (Massarwe, Verner, \& Bshouty, 2010). Comments from the learners indicated that some of their enjoyment was connected to being involved in group work but, like the previous set of learners, also doing something with the designs, rather than simply working with them abstractly, was appreciated:

\footnotetext{
Salam: $\quad$ First time ever that I understand geometry.

Yusof: $\quad$ I discovered that geometry has a special magic and that it is important.

Nimr: $\quad$ I very much enjoyed it. The group work drew us close.

Hanna: Not only theorems and proofs - it is an enjoyable experience of discovering and drawing.

Ranya: $\quad$ I would prefer to study geometry this way. (Massarwe et al., 2010, p. 17)
}

In other places, the implementation of ethnomathematics units evoked similar comments about the need for mutuality of learning (Biddy, 2009). In describing a mathematics lesson on the 
Andean flute, zampoña, Favilli and Tintori (2004) provided comments from five teachers and their students. The students' comments came from a questionnaire and of those quoted many talked about how they worked together:

- What I really liked about the zampoña lessons was the way we all worked together and the new experience.

- The thing I liked most of all about the zampoña lessons was being able to work all together: we were a real team, just like a real family; I also liked it when we found the mathematical law, because we were all enthusiastic, we felt like ... important mathematicians. (p. 44)

When ethnomathematical activities are introduced into the mathematics classrooms where there are Indigenous students, traditional interaction patterns need to be respected. Lipka et al. (2005) described how one teacher supported learners' use of gestures to describe their ideas in collaborative discussions, even to the degree that talking was replaced. Thus, "the safe learning environment, in which nonverbal communication was honored as a cultural way of 'talking' and communicating mathematically in the classroom, allowed [the learner] to take a leadership role and contribute her knowledge in a culturally congruent way" (p. 379). Mutuality of learning may be achieved in a range of ways.

Relationships with artefacts were also valued by learners. In Favilli and Tintori's (2004) project, it was clear that the artefacts used in the lesson supported learners' engagement and thus also their reflection about how they liked to learn:

- The thing I liked about the zampoña lessons was that ... now I know how to make one!

- The thing I liked about the zampoña lessons was seeing something we had made working, and working well because some of our classmates even played a tune with it.

- The work was good fun and, to tell the truth, I really like manual work. (Favilli \& Tintori, 2004, p. 41)

The teachers' comments suggested that the learners had gained mathematical understanding from being involved. Nonetheless, according to Pais (2011), the zampoña was not from the culture of the learners and there is little evidence that cultural considerations in which the zampoña was embedded were discussed in any detail. Thus, there was a risk of trivializing the culture of the activity and this could result in a narrowing of horizons in respect to out-of school contexts. If the activities are not related to contexts with which the learners were familiar outside of the classroom, what contexts are learners being transitioned between? Or is it sufficient that enjoyment of making the flute supported learners' transition into the context of the mathematics classroom?

In other ethnomathematical activities, like the Arab geometric unit, the connection to the cultural background of the learners was evident. These examples suggested that learners' horizons of possibilities for futures were broadened, in regard not just to the school context but also to their home contexts. After the implementation of an ethnomathematics unit in nine Grade 5 Maldivian classrooms, Adam (2003) had learners complete a survey. Their comments indicated that they valued the connection between activities done outside of school and mathematics.

I can understand mathematics better now ... I know how to use formulae and things better after seeing how people do things in [for example] construction of houses. (p. 47)

Before the measurement topic was taught, I did not think of mathematics outside school. Now I see mathematics everywhere. On the street ... Mum also uses measurement in cooking - to measure the rice. At the fish market to sell the fish. (p. 46)

Similarly, at a teacher education college in Israel, prospective Bedouin and Jewish teachers presented projects in which they had identified the mathematics in cultural activities (Katsap \& Silverman, 2008). The following quotations from two Bedouin prospective teachers illustrate how they found the activities stimulating and supportive of their learning:

A subject that I did not previously like, such as the theory of different symmetries, I saw suddenly in a new way in this course, after it was connected to the culture of my people. It was easy to understand and 
I now like it, and therefore I definitely think that the process of exposing the teacher to the cultural aspects of the mathematical ideas is one that contributes to the training of the teacher. (p. 96)

I was very happy during the presentation ... because the material was linked to our culture, and everyone is proud when other people learn and become acquainted with their own culture... I've noticed during the presentation of the study unit that the participating teachers showed considerable interest and desire to learn about our culture... Our group prepared many examples of embroidery and in one activity Jewish teachers were asked to describe orally the transformation types revealed by this example. At the end of the lesson the teachers described their sensations during this task. The satisfaction they've felt was evident. (p. 91)

For many prospective teachers, learning about their own culture through mathematics was a surprise. It also surprised them that other prospective teachers who did not share their religion/culture were interested in the activities.

The activities seemed to broaden learners' horizons in regard to possibilities for their futures outside of formal mathematics education situations. Katsap and Silverman (2008) commented on how the activities contributed to dialogue:

In a lesson on the concept of time presented by a Jewish group, the discussion ranged from the philosophical understanding of the concept to mathematical insight. When a Bedouin student presented his own position on the matter without referring to his culture's attitude, one of the presenters immediately said, "Why are you presenting this example? It would be better if you told us how you view time in the desert. What does your sheikh (literally, "elder") think about the essence of time?" ... In any other class, a political argument could have easily ensued. However, in this case, the Bedouin prospective teacher began to relate how Bedouin religious leaders saw the concept of time. Everyone listened with interest, as moments before the class had discussed the Western attitude of "time is money." Two opinions from the two respective cultures represented their emotional perceptions of time and their cognitive mathematical perceptions of time. (pp. 86-87)

Lipka and Adams (2004) summarized similar comments by learners about how they could relate to the mathematics activities which were set in cultural contexts. However, they also provided examples where the use of materials was not received as had been expected. In one instance, learners told their teacher that they did not want to do the activity because they were already familiar with it.

It would seem that learners engaged with the ethnomathematics activities because the activities were of interest to them and/or because they made connections between different contexts that they were transitioning. It may be that the value given to knowledge that originated outside of the mathematics classroom enabled them to reflect on the sorts of the connections that could be made as they transitioned both into and out of the classroom. Many activities allowed learners to interact with each other and artefacts in collaborative, dialogical ways which supported them as they developed mathematical understandings. However, more research is needed to understand better how and if learners' horizons for future possibilities were broadened as a result of working with ethnomathematics projects.

\section{Critical Mathematics Education}

There are two main geographical groups of critical mathematics educators. Notwithstanding, both groups often refer to each other's theoretical positions and the distinctions between them are not large. One group located in Europe, but with connections to Brazil (see Campos, Wodewotzki, Jabobini, \& Lombardo, 2010), uses the work of Ole Skovsmose who was influenced by the Frankfurt School of Critical Theory (Skovsmose, 2004). Critical theorists aimed at "'emancipating' people from positivist 'domination of thought' through understanding their circumstances and taking action to change their situation" (Patrick, 1999, p. 86). The other group, mainly in America, uses the ideas of Marilyn Frankenstein (2010) on critical mathematical literacy. She drew her inspiration from Paolo Freire. In a re-issue of her first paper, Frankenstein (2010) wrote: 
Freire's theory compels mathematics teachers to probe the non-positivist meaning of mathematical knowledge, the importance of quantitative reasoning in the development of critical consciousness, the ways that math anxiety helps sustain hegemonic ideologies, and the connections between our specific curriculum and the development of critical consciousness. In addition, his theory can strengthen our energy in the struggle for humanization by focusing our attention on the interrelationships between our concrete daily teaching practice and the broader ideological and structural context. (p. 9)

Following the suggestions that Freire made about teaching literacy to adults, Frankenstein (2010) suggested that the problems that learners engage in should be drawn from their own experiences and this would become the starting point for the curriculum. From a philosophical perspective, Skovsmose (2004) identified critical mathematics education as "a preoccupation with challenges emerging from the critical nature of mathematics education. Critical mathematics education refers to concerns which have to do with both research and practice, and a concern for equity and social justice being one of them" (p. 1).

With Helle Alrø, Skovsmose described the need to build learners" "mathemacy" which by connecting to their own contexts empowers their mathematics learning (Alrø \& Skovsmose, 2002). A slightly different interpretation, but one still with an emphasis on empowerment, is that of Ernest (2002):

A successful critical mathematics education must succeed in empowering the learner, first to overcome internal inhibitions and perceptions of inadequacy, second to question the teacher, the subject, and the constraints of school, and third to question the "facts" and edicts of authority at large in society. (p. 1)

Similarly, Frankenstein (1998) suggested that there are four aims for a critical mathematical literacy curriculum:

1. Understanding the mathematics.

2. Understanding the mathematics of political knowledge.

3. Understanding the politics of mathematical knowledge.

4. Understanding the politics of knowledge. (p. 1)

As Jablonka and Gellert (2010) stated, "critical mathematics literacy intends to be simultaneously a pedagogy of access and a pedagogy of dissent" (p. 43). However, it is not easy for educators to resolve the inherent tension between these two aims (Powell \& Brantlinger, 2008), nor for learners to achieve them because of the high level of reflection required.

An examination of the pedagogical practices advocated by critical mathematics educators illustrates how difficult this tension is to resolve. Alrø and Skovsmose (2002) advocated the inquiry cooperation model (see Figure 1), which emphasizes the role that the teacher has to play in listening to learners' contributions both as they meet and then engage with a new problem. The teacher must listen respectfully to the learners but also challenge their reasoning. "Challenging good reasons, therefore, means making the students reflect upon and widen their perspective and knowledge" (Alrø \& Skovsmose, 1996, p. 33).

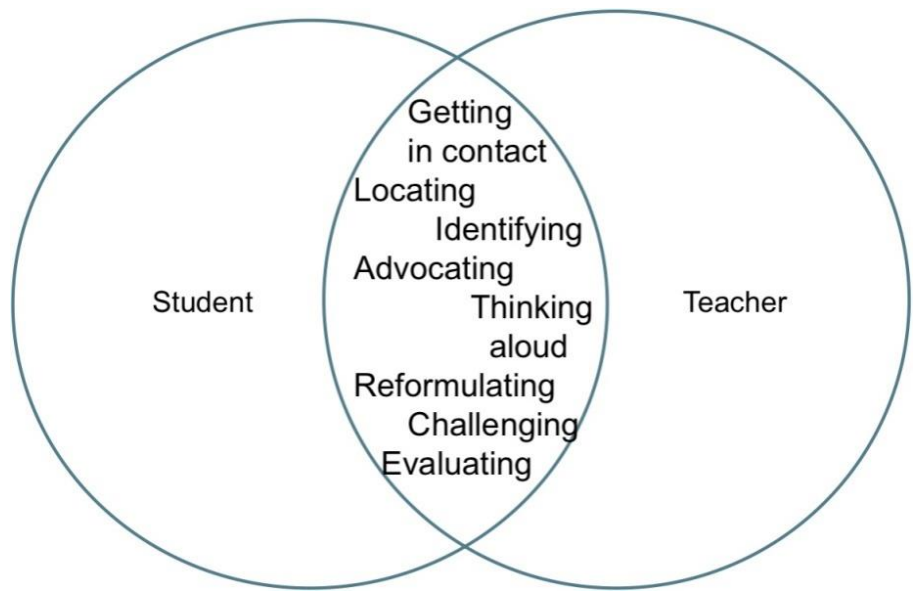

Figure 1. Inquiry co-operation model (from Alrø \& Skovsmose, 2002, p. 63). 
Alrø and Skovsmose (1996) found few examples in their empirical data of teachers actually engaging learners in dialogue similar to that of the inquiry co-operation model. As well, in a discussion of an project, called "Terrible Small Numbers," done with 15- and 16-year-olds about the sampling of eggs for salmonella, Alrø and Skovsmose (2002) wrote: "Terrible small numbers' in principle provided topics for reflection, which in principle may face the challenge of critique. But as experienced by the students, the reflections were not developed into any powerful ideas of critique" (p. 229).

In his research on how four teachers incorporated culturally-relevant teaching ideas into their mathematics lessons, Matthews (2003) reported that only one teacher combined developing learners' mathematical understanding with critiquing their situation with any degree of success. Matthews suggested that this teacher was successful because she built strong relationships with her students based on traditional Bermudian understandings about friendship. The pedagogical practises of this teacher were similar to those advocated by in the inquiry co-operation model (Alrø \& Skovsmose, 2002), as the successful teacher expected learners to work together to justify the appropriateness of their answers. The inquiry co-operation model is in alignment with the conception of pedagogies as relationships as it requires teachers both to hear the learners' contributions and to value them.

\section{Learners' Perspective on Critical Mathematics Education}

As was the case with ethnomathematical pedagogical practices, learners involved in critical mathematics education activities responded positively to them. Again this seemed to be related to how learners were expected to work together as well as finding the project work interesting. One difference with ethnomathematics activities was that learners seemed to have more choices in regard to the project work that they did. Critical mathematics education projects also supported learners to make transitions both into mathematics classrooms but also to outside-school contexts, thus broadening their horizons for future possibilities in multiple directions.

Moreira and Carreira (1998) describe an activity in a calculus class for Portuguese students completing a business degree. Although the class did not include critical mathematics goals, "some of the problem situations used in teaching mathematical topics were suitable for promoting the act of acquiring a new consciousness" (p. 4). In the following extract, the students used a mathematical model to explore income distribution in an imaginary country.

\footnotetext{
Miguel: $\quad$ Now we just need to compute $f(0.5)$.

Paulo: $\quad$ Which gives $25 \%$.

Miguel: $\quad$ So $25 \%$ is the income of the poorest half of the population. This means that the other half is receiving $75 \%$. It's a striking difference!

Cristina: What are you saying? I don't get it.

Paulo: He's saying that the first half, which is the worse paid, gets $25 \%$ of the total income. Therefore, the second half is receiving all the remaining, that is $75 \%$. These are the better paid, they're the richer people.

Cristina: $\quad$ Sure, according to this model ...

Eduardo: Yeah [speaking with an ironic tone in his voice], I doubt that the income can ever be so unfairly distributed.

Isabel: Well, you'd better not!

Eduardo: OK. Let's move on to this one: how do you interpret the fact of having $f(0)$ equal to 0 and $f(1)$ equal to 1 ?

Paulo: Well, if there's no population there can't be any distribution of incomes.

Eduardo: No people, no income.

Paulo: $\quad$ The $f(1)$ equals 1 means that $100 \%$ of the people receive the whole income.

Eduardo: Exactly.

Isabel: $\quad$ Which means that there is no embezzlement of money.

Cristina: There's no sense here to speak of an embezzlement of money ...

Isabel: I mean that there are no false donations, no frauds, no fake payments, no funds deviations and no tax evasions.
} 
Eduardo: You're making a good point there ... (Moreira \& Carreira, 1998, pp. 4-5)

In the exchange, learners used their mathematical understandings but also justified their responses from their own experiences: "There is no embezzlement of money." While Cristina saw this as a mathematical exercise, distinct from reality, Isabel and Eduardo interpreted the results from what they knew about the Portuguese economy. The complexity of the situation contributed to them engaging with the problem. This is in direct contrast with Esmilde, an immigrant student in Gorgorió and Planas' (2005) research, who tried hard to bring his knowledge of different housing situations to a mathematical problem about population density. Both his teacher and a nonimmigrant peer rejected his suggestion, only valuing the mathematical content. Consequently, Esmilde withdrew from engaging in the problem, thus narrowing his horizons of possibilities for his future.

In reported studies, many learners expressed varying levels of dislike for mathematics in the initial stages. Gutstein (2003) quoted from one of his middle-grade students who described his learning after two years of being involved with critical mathematics education as:

Well, I thought of mathematics as another subject in school that I hated. And I didn't bother to think too much about world issues or everyday issues. Now I know it all relates. And I've learned how powerful math can be to help us explain our decisions and help us express ourselves because, like I said before, math makes things more clear. (p. 61)

Critical mathematics education seems to have the possibility to broaden learners' horizons for future possibilities both within a school context but also in relationship to wider societal contexts, that included learners' own foregrounds and considerations of the sort of world that they wanted to live in. Thus, the horizons for future possibilities seemed to be broadened in a multitude of directions.

In Andersson's (in press) research, learners in two classes worked in groups on projectssuch as working out each learner's carbon footprint - that she [Anderrson] deemed as being related to societal contexts and likely to support critical reflections. One of Anderssons' end-ofhigh school learners, Sandra, stated:

What surprised me most though was how important a role mathematics plays when talking about environmental issues. With support of mathematics we can get people to react and stop. [...] I am so interested in environmental questions and did not actually believe that maths could be important when presenting different standpoints. (p. 7)

The projects described by Moreira and Carreira (1998), Gutstein (2003) and Andersson's (in press) appear to have been designed without soliciting the learners' opinions on the sorts of projects in which they would like to engage. This lack of consultation could be in conflict with learners' preference for being seen and valued and also leaves learners as the mediators of the transitions between different contexts. Although the activities seemed to have broadened learners' horizons both for possibilities for their futures from the school context and from outside-school contexts, more research is needed to better understand this connection.

Gutstein (2003) claimed that the problems he set were from the learners' lived experiences. Dowling (2010) criticized one of Gutstein's problems, random traffic stops, because the premise on which it was based, that the police would know the ethnicity of the drivers before they stopped them, was unlikely to be a reality. One of Gutstein's (2007) own students challenged him similarly in a journal entry about whether racism was a factor in getting house mortgages.

In my first article I said that I thought racism was not a factor; after our second discussion I thought racism was a factor, but I think that we don't really know. Even though the rate for Blacks was 5Xs higher than whites in being rejected, that does not necessarily mean it is racism. It could be because of debt, income, or maybe it could be racism. (p. 58)

Gutstein responded to the learner's comments by discussing the relationship between individual and institutional racism. At the end of the project, he also had learners adopt the perspectives of other participants in the problem, including the bank lenders. The project resulted in much 
discussion and Gutstein hypothesized that it was because the problem was meaningful for the learners. As one learner, Leandro wrote:

This project was very interesting because it has happened to one of my uncles. He was looking for a house and found one. But in the end, he was turned down. This really is important to me because I will like to buy a house when I grow up, not only for me, but for my cousin and my sister. (Gutstein, 2007, p. 61)

Others have noted a similar impact on statistical learning when the topics were important to the learners. In work with student teachers in Columbia, Rojas (2010) found that "the students learned to use these statistical tools and concepts in the context of identifying and addressing the most pressing problems facing their own communities"(p. 3). In Brazil, a group of medical researchers worked with sixth-grade students in high poverty areas on how to interpret statistical data about mouth cancer so that they could then present this information to their families (Sundefeld, Homse, Prieto, \& Rodrigues, 2010). By the end of the project, students had increased their understanding both about mouth cancer and also statistics. Many of their families commented that they had learnt a lot from their children about mouth cancer, although their statistical knowledge had not improved. This was the only project which seemed to investigate learners transitioning into out-of-classroom contexts explicitly.

Having learners engage in topics that investigate inequities can mean that children deal with adult topics. Stocker and Wagner (2007) discussed some of the ethical tensions arising from this. In support of his argument for using mathematics to understand social justice issues better, Stocker quoted two of his 12- and 13-year-old students:

If we don't know about social issues, if we don't learn to be critical, we won't form views of our own. We'll grow up in a politically impotent society.

Only through learning can things change. Schools need to teach this stuff. Children can't be hidden from the world. (p. 19)

Similarly, Gutstein's (2003) learners felt that being involved in considering societal issues which required them to understand mathematics was important.

\begin{abstract}
Also, I thought math was just a subject they implanted on us just because they felt like it, but now I realize that you could use math to defend your rights and realize the injustices around you. I mean you could quickly find an average on any problem, find a percentage on any solution, etc. I mean now I think math is truly necessary and I have to admit it, kinda cool. It's sort of like a pass you could use to try to make the world a better place. (p. 62)
\end{abstract}

In her work with adult learners, Tomlin (2002) requested them to bring in problems that they found relevant and which required mathematics. Although one student's problem fitted the criteria, it could be solved more sensibly, through the combined wisdom of classmates, in ways which did not involve using mathematics. Civil (n.d.) commented that in real-world problems, "mathematics is often hidden; it is not the center of attention and may actually be abandoned in the solution process" (p. 27).

Although learners could not choose their own problems in Andersson's (in press) projects, there was some room for them to make some choices, and that was appreciated. The following comment is again from Sandra, who had described herself as having maths anxiety:

\footnotetext{
We distributed the time well, I think. [...] The group worked well. We were good at different things and helped each other. I am proud of the work I have done as I felt I could contribute a lot in the beginning when we talked about borrowing money and interest rates. To plan time and content [my]self got me to feel it related to me. I think mathematics has been a little more fun than usual. [...] I feel the project has been meaningful and to look at mathematics from different angles (vändra och vrida på matematiken) was positive. But I would like more time for explanations from the teacher, as mathematics is difficult for me. (Andersson, in press)
}

For Sandra, the pedagogical approach seemed to respect her need to be seen and valued. "I felt in that I could contribute a lot," and "the group worked well. We were good at different things and helped each other." Working in groups seemed to support her to overcome her anxiety about 
mathematics which can be seen as one form of transition. Nevertheless, the final cry about needing more help from the teacher suggests that she had not yet come to see herself as being a capable learner of mathematics. At the end of the project on carbon footprints, Sandra wrote:

I have probably learnt more now than if I had only calculated tasks in the book. Now I could get use of the knowledge in the project and that made me motivated and happy! I show my knowledge best through oral presentations because there you can show all the facts and talk instead of just writing a test. To have a purpose with the calculations motivated me a lot. (Andersson, in press)

Activities linked to critical mathematics education seemed to support learners' reflections on their learning both of content knowledge but also about themselves. These reflections enabled learners to see connections to their backgrounds, their foregrounds and their hopes for the future of the world. Thus, they could be said to support them transitioning between contexts - into and out of the mathematics classroom - thereby broadening their horizons for their future possibilities in more than one direction.

\title{
Modes of Belonging
}

In order to analyze learners' perceptions, we draw on Wenger's (1998) modes of belonging. Nasir and Cooks (2009) suggested that Wenger "reconceptualizes learning from an in-the-head phenomenon to a matter of engagement, participation, and membership in a community of practice" (p. 42). The modes of belonging indicate how people position themselves in relationship to communities of practice, and thus the forms of becoming that are possible. Commonly, mathematics classrooms are considered to be communities of practice.

\begin{abstract}
The recognition of the mathematics classroom as a functioning community where teacher and student activity in it is shaped by (and shapes) a set of norms and practices for learning mathematics highlights the importance of issues such as competence, ownership and alignment in engaging in this community. In particular alignment between practices and identities of home and school has implications for whether students negotiate ways of participating that serve their individual goals (Cobb \& Hodge, 2002; Hand, 2003). (DiME, 2007, p. 408)
\end{abstract}

Consequently, it would seem that the ultimate goal is to understand how learners transition into the community of practice of the mathematics classroom. Yet this view of a mathematics classroom tends to decontextualize it from the "larger social, cultural, economic and political structures" (Valero, 2010, p. LXI) that influence what occurs within those classrooms. In contrast, we see membership of the mathematics classroom community of practice as only one outcome of the never-ending transitioning process and one that occurs concurrently with learners transitioning from the classroom context into outside-classroom contexts such as the home. Therefore, we use modes of belonging to consider how pedagogical approaches support learners to transition between contexts in ways that broaden rather than narrow their horizons of possibilities for their futures in a number of directions. Figure 2 summarizes the three modes of belonging: engagement; imagination; and alignment.

According to Wenger (1998), engagement has three parts: "the ongoing negotiation of meaning," "the formation of trajectories," and "the unfolding histories of practice" (p. 174). The distribution of power affects participants' willingness and ability to engage and conversely engagement "affords the power to negotiate our enterprises and thus to shape the context in which we can construct and experience an identity of competence" (p. 175). Although some practices are engaged in many times, each new experience will need to be made sense of again, leading to an evolution of these practices. Continual negotiation of meaning within familiar and unfamiliar situations contributes to the formation of trajectories. "As trajectories, our identities incorporate the past and the future in the very process of negotiating the present" (p. 155). However, "the understanding inherent in a shared practice is not necessarily one that gives members broad access to the histories or relations with other practices that shape their own practices" (p. 175). 


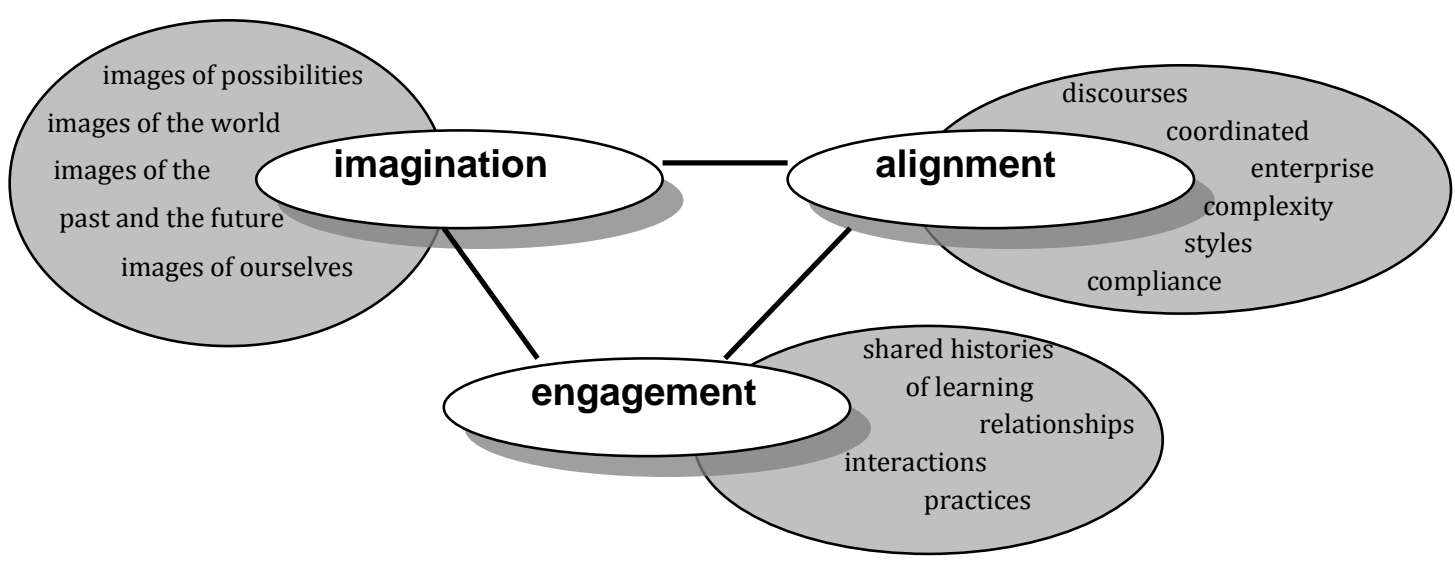

Figure 2. Modes of belonging. (from Wenger, 1998, p. 174).

Imagination is embedded within "our own experience" (Wenger, 1998, p. 173). Like Radford's view of learning, imagination arises in the interaction between the individual and in Wenger's case the community of practice. In retelling a story about two stone-cutters who gave different responses when questioned about what they saw themselves as doing when chiselling a block of stone, Wenger (1998) stated: "Their experiences of what they are doing and their sense of self in doing it are rather different. This difference is a function of imagination. As a result, they are learning very different things from the same activity" (p. 176). Imagination is closely linked to whether learners perceive the process of transitioning between contexts as leading to a narrowing or widening of their horizons of possibilities for their futures.

For Wenger (1998) "the process of alignment bridges time and space to form broader enterprises so that participants become connected through the coordination of their energies, actions, and practices" (p. 179). Although alignment is usually connected to both engagement and imagination, it may not be. Some learners in mathematics classrooms may complete textbook exercises and have a clear sense of what it means to be a mathematics learner, but when an opportunity arises to withdraw from taking mathematics classes they do so because they do not want to align themselves with this practice (Ingram, 2011). Coerced alignment may impact on the belonging that learners ultimately assume.

\section{Modes of Belonging: Ethnomathematics and Critical Mathematics Education}

From the learners' perspectives, pedagogical practices, based on ethnomathematics and critical mathematics education seem to have features that support them to transition between contexts. Nevertheless, researchers considered that both sets of approaches have some inherent tensions arising from multiple and sometimes conflicting assumptions. On the other hand, learners' perceptions, as reported in research reports, suggest that they were not concerned with these tensions. Generally, learners verified that learning experiences based in ethnomathematics and critical mathematics education provided them simultaneously with mathematical skills and an awareness of outside school issues. Analyzing the comments using Wenger's modes of belonging indicated that working as a group on complex problems that the learners cared for were features that supported learners to transition between contexts.

\section{Engagement}

The learners' comments indicated that they engaged in the projects and so reflected on what mathematics was, how it could be used and how it should be learnt. Often the projects spanned several lessons and in some instances, learners worked on them at home. However, the transition 
into home contexts, and their engagement in activities there, was the focus of only one research study (Sundefeld et al., 2010).

Teachers and facilitators often assumed a shared history with learners when choosing an activity. Usually, the activity was seen as the vehicle for connecting the learners' backgrounds to improved school mathematics understanding, which was an important consideration in learners' foregrounds.

The negotiation between familiar and unfamiliar situations could contribute to the formation of a trajectory. However, there is a need to recognize the impact of learners' own perceptions of their situation on their dispositions to learn. Andersson (2010) commented on how labelling a day, set aside for project work about the United Nations Rights of the Child, as a Maths Day meant that many students chose to attend doctor and dentist appointments. One student, Petra, stated:

First I thought, a whole day of mathematics, I can't do it; I just can't be there the whole day. But when I got there it was actually quite fun and now, afterwards, I read and look in the newspapers in a different way. So I actually learnt something that was really unexpected of a math-day. (p. 14)

In the critical mathematics education projects, learners were supported to engage by being able to make choices about aspects of the projects, although not usually the topic of the projects. In the ethnomathematics activities, learners commented on the value of being physically involved in an activity, such as playing games and making flutes. This increased their interest and supported them to reflect on both the activity and mathematics in different ways. It would have been valuable to know whether they also engaged in these activities outside of the classroom so that the activities could be considered as easing their transition in that direction as well.

Project work provided learners with opportunities to form supportive and collaborative relationships that contributed to developing a shared history of learning. A requirement to present to others supported learners to share more than just information about the project (e.g. Katsap \& Silverman, 2008). This has links to Biddy's (2009) learners' requests for mutuality in learning.

When learners worked in groups to solve challenging problems, power was not located within the teacher but flowed between the participants. Sundefeld et al.'s (2010) project showed that school children could take on the role of informants to their families. Again, it would have been valuable to know how this eased their transition from school to out-of-school contexts.

\section{Imagination}

Imagination is closely connected to learners considering themselves as being seen and valued. For this to occur, learners need to reflect on how they are learning. Often project work supported the learners to see that mathematics could be used in situations that were important to them. In Gutstein's critical mathematics education projects, learners began to understand the power of mathematical ideas and this provided a motivation for them to want to learn. In the gardening project described by Civil's (n.d.), the children's devotion to their plants was a surprise to the teacher but supported them to participate in solving the somewhat contrived mathematical problems about the gardens.

When learners could connect mathematics to their interests, they could imagine engaging in future tasks that required them to use mathematics. However, some learners did not immediately embrace the idea that it was mathematics that provided them with these possibilities. The following quote from one of Andersson's learners, Zizzie, exemplifies this tension for the learner:

A math-day, how fun could that be, and why did you call it a math-day? We worked on posters, we sought information, we rewrote mathematics stuff for best effect, but that is not mathematics! It was a really good day, but definitely not maths. (Andersson, 2010, p. 15)

Imagination of future possibilities was connected to the learners' experiences with mathematics in the past (Patrick, 1999). Allowing spaces for discussion of different facets of the activities meant that they were opened to discussion and reflection. This is likely to broaden horizons for 
imagining future possibilities for school mathematics. However, the relationship to transitions to outside-school contexts is not so clear.

\section{Alignment}

On the whole, the learners aligned themselves with the aims of the ethnomathematics and critical mathematics agendas to which they were introduced. This can be seen in the way that they combined their everyday knowledge, interests and mathematical understandings when working on the different activities. Yet, some learners had to be encouraged to align themselves with the activities by a teacher or in some cases an elder (Lipka \& Adams, 2004).

It was not always clear how learners' changed perceptions of mathematics and how it could be learned were connected to their willingness to align themselves with mathematics activities in the future. As one of Gutstein's (2003) learners stated "I think that now I can understand the world better by using math, but that doesn't mean I like connecting math with what surrounds me. I still think that there are some "big ideas" you can understand without using math" (p. 61). This learner may have learned to tolerate doing mathematics in the classroom but was unlikely voluntarily to choose to use mathematics in situations outside the classroom. The transition into the mathematics classroom was eased but the mathematical knowledge was likely to remain compartmentalized as something done at school.

For other students, the power that they gained from solving problems that mattered to them, with mathematics, supported their continuing engagement in mathematics classrooms. By enrolling in courses, adult learners - such as those described by Tomlin (2002) and Patrick (1999) - showed that mathematics learning was an enterprise with which they wished to align themselves. This was the case even though their imagination of mathematics seemed clearly connected to what they had not been able to do when at school.

By using the modes of belonging as a lens, it is possible to see that activities based on ethnomathematics or critical mathematics education approaches provided possibilities for easing learners' transitions into mathematics classrooms. This is because it enabled learners to see possibilities about why they should learn mathematics. This was not possible when connections were not made to their backgrounds, foregrounds or to improving the world in which they lived. Nevertheless, although the activities provided opportunities for learners to engage in, imagine and align themselves to learning mathematics at school, there were still tensions when teachers'/facilitators' assumptions about the activities did not match those of the learners. The focus of activities was on easing learners' transition into the mathematics classroom and only secondary consideration, if any, was given to easing learners' transition into out-of-school contexts.

\section{Transitioning Into and Out of School Mathematics Contexts}

In this chapter, we have defined contexts as systems of knowledge. Transitioning contexts, therefore, involved coming to terms with differences in knowledge, how it was organized and valued and the interaction patterns around how it was used. Learners' reflection on these differences led to learning, both about the knowledge but also about the learners themselves. When the knowledge system of school mathematics was similar to those of outside-school contexts then the transitioning process was likely to lead to a broadening of horizons of possibilities for learners' futures, in both the school and out-of-school directions. However, when there were differences, then transitioning could leave learners as the mediators between knowledge systems. This could result in a narrowing of learners' horizons in regard to school mathematics learning and out-of-school learning.

In this final section, we first discuss why learners' perspectives are so important before revisiting Willis' table showing the relationship between disadvantage, mathematics education 
and curriculum. Then, we summarize those practices that seemed to ease learners' transitioning and conclude with suggestions for further research.

If we take seriously the proposition that learning occurs when learners transition between contexts and that it includes a process of becoming, as well as understanding content, then it is important to consider the pedagogical practices from the learners' own perspectives. It is their understanding of the activities that enables connections between their foregrounds and backgrounds to form their dispositions to learn (Skovsmose, 2004). As can be seen in the modes of belonging analysis, regardless of the pedagogical approaches adopted, learners' perceptions may be different from the perceptions of those who develop the mathematical activities. This can lead to a narrowing of horizons of possibilities for learners' futures, both in regard to formal mathematics and to out-of-school activities. Nevertheless, in the studies described, ethnomathematics and critical mathematics education approaches did seem to support learners to transition between in-school and out-of-school contexts, at least in one direction-towards school—and thus broadened horizons from this viewpoint.

Ethnomathematics and critical mathematics education have similarities with Perspectives 3 and 4 in Willis' (1998) table (see Table 1). As described earlier, the perspectives appear to position some groups as being other, so the focus remains of their differences. By investigating pedagogical approaches, we instead focus on the relationship between transitioning and the narrowing or broadening of horizons of learners' possibilities for their futures. Using learners' perspectives means that although their reflections form the heart of the analysis, it is the approaches and the outcomes of the approaches which are discussed.

The features that the learners suggested supported their transitioning process varied between what was learnt and how it was learnt. On the whole, learners suggested that activities had to be based on something that they cared for: in their past, such as poor performance in mathematics when at school; in their future, for example using ethnomathematical activities themselves as teachers; and in their present, cultivating a garden and growing plants. Learners also valued activities which were socially or politically motivating for them-such as investigating issues to do with climate change. The activities in which learners were interested generally involved integrating knowledge systems from inside and outside school.

The relevance of Biddy's (2009) pedagogy of relationship was obvious in learners' comments about how they should learn. For example, they valued being seen and valued, not only by their teachers but also by other learners. Being able to negotiate aspects of the activities with each other and with the teacher was one component of this, and this contributed to them aligning themselves with the present activities. Working in collaborative groups that had to resolve complex issues meant that all learners had to contribute, and those contributions were seen as valuable. The continuing negotiation within the groups, with the teacher, and in relation to the artefacts with which they had to work, meant that power was distributed between participants. The learners enjoyed working with interesting artefacts - such as the Andean flute-for these supported their engagement in mathematics classroom activities. Many learners commented on the value of "learning by doing." However, when the tasks were not explicitly linked to the learners' own culture, the only transitioning that the tasks supported was into the classroom.

Learners have valuable insights into the sorts of pedagogical practices that contribute to them transitioning between contexts. Over the last few decades there has been much theorizing about reasons why certain groups of learners do not do well in mathematics classrooms. These have lead to awareness that learners' backgrounds and their expectations about what they can learn in the classrooms will contribute to their dispositions to learn. Yet this has not led to a proliferation of research that asks learners about their experiences. In this chapter, we have presented much of the research that is available. Nonetheless, there is a need for more work if we are to learn how to ease learners' transitioning processes so that their horizons of possibilities for futures are enlarged rather than reduced. We do not know, for instance, whether enjoyment of an 
activity in itself eases learners' transitioning between contexts or whether there is a need to bridge different knowledge systems with which learners are familiar.

As well we would suggest that further work needs to be done in regard to improving our understanding of the range of contexts that are likely to facilitate learners' transitions. In our analysis, it was clear that both ethnomathematics and critical mathematics education have the potential to ease the transitioning of learners into out-of-school contexts. However, this has rarely been the object of mathematics education research, which has remained focussed on transitioning into mathematics classrooms. Countries' obsession with national testing, with equity issues being strongly tied to increased test results, has blinkered much of the research, leading to a focus on the importance of easing learners into the mathematics classroom. Yet it is naïve to believe that learners would form dispositions to learn simply from their experiences in those classrooms. The reflection in which learners engage as they transition into out-of school contexts, including the home, is likely to have an equal impact on their dispositions to learn, within those very classrooms which are deemed to be so important.

\section{References}

Adam, S. (2003). Ethnomathematical ideas in the curriculum. In L. Bragg, C. Campbell, G. Herbert \& J. Mousley (Eds.), Mathematics Education Research: Innovation, Networking, Opportunity: Proceedings of the 26th Annual Conference of the Mathematics Education Research Group of Australasia (pp. 41-48). Melbourne, Australia: Mathematics Education Research Group of Australasia. Retrieved from http://www.merga.net.au/publications/counter.php?pub=pub_conf\&id=1336

Alrø, H., \& Skovsmose, O. (1996). Students' good reasons. For the Learning of Mathematics, 16(3), 31-38.

Alrø, H., \& Skovsmose, O. (2002). Dialogue and learning in mathematics education: Intention, reflection, critique. Boston, MA: Kluwer Academic Publishers.

Andersson, A. (2010). Can a critical pedagogy in mathematics lead to achievement, engagement and social empowerment? Philosophy of Mathematics Education, 25. Retrieved from http://people.exeter.ac.uk/PErnest/pome25/index.html

Andersson, A. (in press). Interplays between context and students' achievement of agency. In Proceedings from 7th Conference for European Research in Mathematics Education, February 9-13, 2011, Rzeszów, Poland. Retrieved from

http://www.cerme7.univ.rzeszow. pl/index.php?id=wg10

Anthony, G., \& Walshaw, M. (2007). Effective pedagogy in mathematics/pangarau. Wellington. New Zealand: New Zealand Ministry of Education. Retrieved from http://www.educationcounts.edcentre.govt.nz/publications/series/ibes/effective_pedagogy_i n_pangaraumathematics

Ascher, M., \& Ascher, R. (1986). Ethnomathematics. History of Science, 14, 125-144.

Atweh, B., \& Brady, K. (2009). Socially response-able mathematics education: implications of an ethical approach. Eurasia Journal of Mathematics, Science \& Technology Education, 5(3), $267-276$.

Barta, J. (2002). The mathematical ecology of the Florida Seminole and its classroom implications. In W. Secada (Ed.), Changing faces of mathematics: Perspectives on Indigenous people of North America (pp. 167-174). Reston, VA: National Council of Teachers of Mathematics.

Barta, J., \& Brenner, M. E. (2009). Seeing with many eyes: Connections between anthropology and mathematics. In B. Greer, S. Mukhopadhyay, A. B. Powell \& S. Nelson-Barber (Eds.), Culturally responsive mathematics education (pp. 85-110). New York: Routledge. 
Barton, B. (2004). Mathematics and mathematical practices: Where to draw the line? For the Learning of Mathematics, 24(1), 22-24.

Biddy, T. (2009). How do pedagogic practices impact on learner identities in mathematics? In L. Black, H. Mendick \& Y. Solomon (Eds.), Mathematical relationships in education: Identities and participation (pp. 123-135). New York, NY: Routledge, Taylor and Francis.

Bishop, A. J. (2004). Critical issues in researching cultural aspects of mathematics education. Paper presented in Discussion Group 2, 10th International Congress on Mathematics Education, Copenhagen, Denmark. Retrieved from http://www.icme-organisers.dk/dg02/

Borba, M. C. (1990). Ethnomathematics in education. For the Learning of Mathematics, 10(1), $39-43$.

Brenner, M. E. (1998). Meaning and money. Educational Studies in Mathematics, 36(2), 123-155.

Brown, R. (2009). Teaching for Social Justice: Exploring the Development of Student Agency through Participation in the Literacy Practices of a Mathematics Classroom. Journal of Mathematics Teacher Education, 12(3), 171-185. doi:10.1007/s10857-009-9110-7

Cahnmann, M. S., \& Remillard, J. T. (2002). What counts and how: Mathematics teaching in culturally, linguistically, and socioeconomically diverse urban settings. The Urban Review, 34(3), 179-204.

Campos, C. R., Wodewotzki, M. L., Jabobini, O. R., \& Lombardo, D. F. (2010). Statistics education in the context of the critical education: Teaching projects. In C. Reading (Ed.), Data and context in statistics education: Towards an evidence-based society: Proceedings of the Eighth International Conference on Teaching Statistics (ICOTS8), July, 2010, Ljubljana, Slovenia. Voorburg, The Netherlands: International Statistical Institute. Retrieved from http://www.stat.auckland.ac.nz/ iase/publications.php?show=icots8

Cantoni, G. (1991). Applying a cultural compatibility model to the teaching of mathematics to indigenous populations. Journal of Navajo Education, IX(1), 33-42.

Carraher, D. W., \& Schliemann, A. D. (2002). Is everyday mathematics truly relevant to mathematics education. In M. Brenner \& J. N. Moschkovich (Eds.), Journal for Research in Mathematics Education Monograph: Everyday and academic mathematics in the classroom (Monograph) (pp. 131-153). Reston, VA: National Council of Teachers of Mathematics.

César, M. (2007). Dialogical identities in students from cultural minorities or students categorised as presenting SEN: How do they shape learning, namely in mathematics. In ScTIG Group (Ed.), Second Socio-Cultural Theory in Educational Research and Practice Conference Proceedings. Manchester: University of Manchester. Retrieved from

http://www.education.manchester.ac.uk/research/centres/lta/ltaresearch/socioculturaltheoryi nterestgroupsctig/socioculturaltheoryineducationconference2007/conferencepapers/groupthr eepapers/files/

Civil, M. (n.d.). Building on community knowledge: An avenue to equity in mathematics education. Retrieved 1 June 2011, from:

http://cemela.math.arizona.edu/spanish/content/workingpapers/

Civil, M. (2008 July). Mathematics teaching and learning of immigrant students: A look at the key themes from recent research. Manuscript prepared for the 11th International Congress of Mathematics Education (ICME) Survey Team 5: Mathematics Education in Multicultural and Multilingual Environments, July 2008, Monterrey, Mexico. Retrieved from http://math. arizona.edu/ cemela/english/content/ICME_PME/MCivil-SurveyTeam5-ICME11.pdf

Civil, M., \& Planas, N. (2010). Latino/a immigrant parents' voices in mathematics education. In E. L. Grigorenko \& R. Takanishi (Eds.), Immigration, diversity and education (pp. 130 150). New York, NY: Routledge. 
Cooper, B., \& Harries, T. (2002). Children's responses to contrasting 'realistic' mathematics problems: Just how realistic are children ready to be? Educational Studies in Mathematics, $49,1-23$.

Crafter, S., \& de Abreu, G. (2011). Teachers' discussion of parental use of implicit and explicit mathematics in the home. In Proceedings from 7th Conference for European Research in Mathematics Education, February 9-13, 2011, Rzeszów, Poland. Retrieved from http://www.cerme7.univ.rzeszow.pl/index.php?id=wg1 $\underline{0}$

D'Ambrosio, U. (1992). Ethnomathematics: A research program on the history and philosophy of mathematics with pedagogical implications. Notices of the American Mathematical Society, 39(10), 1183-1185.

D'Ambrosio, U. (2010). Ethnomathematics: A response to the changing role of mathematics in society. Philosophy of Mathematics Education, 25. Retrieved from http://people.exeter.ac.uk/PErnest/pome25/http://people.exeter.ac.uk/PErnest/pome25/

Davis, E. K., Seah, W. T., \& Bishop, A. J. (2009). Students' transition between contexts of mathematical practices in Ghana. In Proceedings of 2009 Mathematics Association of Victoria Conference, (pp. 62-71). Retrieved from http://www.mav.vic.edu.au/files/conferences/2009/10Davis.pdf

de Abreu, G. (1993). The relationship between home and school mathematics in a farming community in rural Brazil. Unpublished doctoral dissertation, Cambridge University, Cambridge, U.K.

de Abreu, G., Bishop, A. J., \& Presmeg, N. C. (2002). Mathematics learners in transition. In G. de Abreu, A. J. Bishop, \& N. C. Presmeg (Eds.), Transitions between contexts of mathematical practices (pp. 7-21). Dordrecht, The Netherlands: Kluwer Academic Publishers.

de Abreu, G., \& Gorgorió, N. (2007). Social representations and multicultural mathematics teaching and learning. In D. Pitta-Pantazi \& G. Philippou (Eds.), Proceedings of the Fifth Congress of the European Society for Research in Mathematics Education 22-26 February 2007, Larnaca, Cyprus, (pp. 1559-1566). European Society for Research in Mathematics Education. Retrieved from http://ermeweb.free.fr/CERME5b/WG10.pdf

Diversity in Mathematics Education Center for Learning and Teaching [DiME] (2007). Culture, race, power and mathematics education. In F. K. Lester (Ed.), Second handbook of research in mathematics teaching and learning (pp. 405-433). Charlotte, NC: Information Age.

Dowling, P. (2010). Abandoning mathematics and hard labour in schools: A new sociology of knowledge and curriculum reform. Keynote presentation at The Seventh Swedish Mathematics Education Research Seminar (MADIF-7), Stockholm, Sweden, January 26-27, 2010.

Ernest, P. (2002). Empowerment in mathematics education. Philosophy of Mathematics Education, 15. Retrieved from:

http://people.exeter.ac.uk/PErnest/pome15/empowerment.htm

Esmonde, I., \& Saxe, G. B. (2004). 'Cultural mathematics' in the Oksapmin curriculum: Continuities and discontinuities. In ICLS '04: Proceedings of the 6th International Conference on Learning Sciences. Retrieved from http://dl.acm.org/citation.cfm?id=1149146\&dl=ACM\&coll=DL\&CFID=46231086\& CFTOKEN $=37114030$

Fairclough, N. (2003). Analysing discourse : Textual analysis for social research. London, UK: Routledge.

Favilli, F., \& Tintori, S. (2004). Intercultural mathematics education: Comments about a didactic proposal. In F. Favilli (Ed.), Ethnomathematics and mathematics education: Proceedings of the 10th International Congress of Mathematics Education Copenhagen. Discussion Group 15 Ethnomathematics (pp. 39-47). Pisa: Tipografia Editrice Pisana. Retrieved from http://www.dm.unipi.it/ favilli/Ethnomathematics_Proceedings_ICME10.pdf 
Frankenstein, M. (1998, July). Reading the world with maths: Goals for a critical mathematical literacy curriculum. Paper presented at the First International Conference of Mathematics Education and Society, Nottingham, UK. Retrieved from http://www.nottingham.ac.uk/csme/meas/measproc.html

Frankenstein, M. (2010). Critical mathematics education: An application of Paolo Freire's epistemology. Philosophy of Mathematics Education, 25. Retrieved from http://people.exeter.ac.uk/PErnest/pome25/index.html

Gadamer, H.-G. (1996). Truth and method (2 ${ }^{\text {nd }}$ ed.). New York, NY: Continuum.

Gee, J. P. (1996). Social linguistics and literacies: Ideologies in discourse. London, UK: Taylor and Francis.

Gorgorió, N., \& Planas, N. (2003). Transitions from backgrounds to foregrounds. In Proceedings for the Third Congress for European Research in Mathematics Education. Retrieved from http://www.dm.unipi.it/ didattica/CERME3/proceedings/Groups/TG10/TG10_Gorgorio_cer me3.pdf

Gorgorió, N., \& Planas, N. (2005). Social representations as mediators of mathematics learning in multiethnic classrooms. European Journal of Psychology of Education, 20(1), 91-104. doi:10.1007/BF03173213

Gutstein, E. (2003). Teaching and learning mathematics for social justice in an urban, Latino school. Journal for Research in Mathematics Education, 34(1), 37-73.

Gutstein, E. (2007). "So one question leads to another": Using mathematics to develop a pedagogy of questioning. In N. S. Nasir \& P. Cobb (Eds.), Improving access to mathematics: Diversity and equity in the classroom (pp. 1-9). New York, NY: Teachers College Press.

Ingram, N. (2011). Affect and identity: The mathematical journeys of adolescents. PhD thesis, University of Otago, Dunedin, New Zealand.

Jablonka, E., \& Gellert, U. (2010). Ideological roots and uncontrolled flowering of alternative curriculum conceptions. In U. Gellert, E. Jablonka, \& C. Morgan (Eds.), Proceedings of the Sixth International Mathematics Education and Society Conference, 20-25 March 2010, (pp. 31-39). Berlin: Freie Universität Berlin. Retrieved from http://www.ewi-psy.fu berlin. de/en/ v/mes6/research_papers/index.html

Katsap, A., \& Silverman, F. L. (2008). A case study of the role of ethnomathematics among teacher education students of highly diverse cultural backggrounds. Journal of Mathematics and Culture, 3(1), 66-102. Retrieved from: http://nasgem.rpi.edu/pl/journal-mathematicsculture-volume-3-number-1http://nasgem.rpi.edu/pl/journal-mathematics-culture-s37

Knijnik, G. (1998). Ethnomathematics and political struggles. Zentralblatt für Didaktik der Mathematik, 30(6), 188-194.

Knijnik, G., Wanderer, F., \& Oliveira, C. J. d. (2005). Cultural differences, oral mathematics and calculators in a teacher training course of the Brazilian Landless Movement. Zentralblatt für Didaktik der Mathematik, 37(2), 101-108.

Laridon, P., Mosimege, M., \& Mogari, D. (2005). Ethnomathematics research in South Africa. In R. Vithal, J. Adler, \& C. Keitel (Eds.), Researching mathematics education in South Africa (pp. 133-164). Pretoria, South Africa: Human Sciences and Research Council. Retrieved from http://www.hsrcpress.ac.za/product.php?productid=2034

Lipka, J., \& Adams, B. L. (2004). Some evidence for ethnomathematics: Quantitative and qualitative data from Alaska. In F. Favilli (Ed.), Ethnomathematics and mathematics education: Proceedings of the 10th International Congress of Mathematics Education Copenhagen. Discussion Group 15 Ethnomathematics (pp. 87-98). Pisa, Italy: Tipografia Editrice Pisana. Retrieved from http://www.dm.unipi.it/ favilli/Ethnomathematics_Proceedings_ICME10.pdf 
Lipka, J., Hogan, M. P., Webster, J. P., Yanez, E., Adams, B., Clark, S., \& Lacy, D. (2005). Math in a cultural context: Two case studies of a successful culturally based math project. Anthropology \& Education Quarterly, 36(4), 367-385.

Lipka, J., Yanez, E., Andrew-Ihrke, D., \& Adam, S. (2009). A two-way process for developing effective culturally-based math: Examples from Math in a Cultural Context. In B. Greer, S. Mukhopadhyay, A. B. Powell \& S. Nelson-Barber (Eds.), Culturally responsive mathematics education (pp. 257-280). New York, NY: Routledge.

Masingila, J. O. (1994). Mathematics practice in carpet laying. Anthropology \& Education Quarterly, 25(4), 430-462.

Masingila, J. O. (1996 July). What can we learn from students' out-of-school mathematics practices? Paper presented at Working Group 21, ICME 8, Seville, Spain.

Masingila, J. O., Davidenko, S., \& Prus-Wisniowska, E. (1996). Mathematics learning and practice in and out of schools: A framework for connecting these experiences. Educational Studies in Mathematics, 31, 175-200.

Massarwe, K., Verner, I., \& Bshouty, D. (2010). An ethnomathematics exercise in analysing and constructing ornaments in a geometry class. Journal of Mathematics and Culture, 5(1), 1 20. Retrieved from: http://nasgem.rpi.edu/pl/journal-mathematics-culture-volume-5-number-1

Matthews, L. E. (2003). Babies overboard! The complexities of incorporating culturally relevant teaching into mathematics instruction. Educational Studies in Mathematics, 53(1), 61-82. Retrieved from: http://dx.doi.org/10.1023/A:1024601504028doi:10.1023/A:1024601504028

Moreira, D. (2007). Filling the gap between global and local mathematics. In D. Pitta-Pantazi \& G. Philippou (Eds.), Proceedings of the Fifth Congress of the European Society for Research in Mathematics Education 22-26 February 2007, Larnaca, Cyprus, (pp. 15871596). European Society for Research in Mathematics Education \& Department of Education, University of Cyprus. Retrieved from http://ermeweb.free.fr/CERME5b/WG10.pdf

Moreira, L., \& Carreira, S. (1998). No excuses to command, not excuses to obey, no excuses to ignore. Some data to reflect upon. In Proceedings of the First International Conference of Mathematics Education and Society, 6-11 September 1998, Nottingham, UK. Retrieved from http://www.nottingham.ac.uk/csme/meas/measproc.html

Morgan, C. (2009). Questioning the mathematics curriculum: A discursive approach. In L. Black, H. Mendick, \& Y. Solomon (Eds.), Mathematical relationships in education: Identities and participation (pp. 97-106). New York, NY: Routledge, Taylor and Francis.

Mosimege, M., \& Ismael, A. (2004). Ethnomathematical studies of Indigenous games: Examples from Southern Africa. In F. Favilli (Ed.), Ethnomathematics and mathematics education: Proceedings of the 10th International Congress of Mathematics Education Copenhagen. Discussion Group 15 Ethnomathematics (pp. 119-137). Pisa, Italy: Tipografia Editrice Pisana. Retrieved from:

http://www.dm.unipi.it/ favilli/Ethnomathematics_Proceedings_ICME10.pdf

Nasir, N. S., \& Cobb, P. (2007). Introduction. In N. S. Nasir \& P. Cobb (Eds.), Improving access to mathematics: Diversity and equity in the classroom (pp. 1-9). New York, NY: Teachers College Press.

Nasir, N. S., \& Cooks, J. (2009). Becoming a hurdler: How learning settings afford identities. Anthropology \& Education Quarterly, 40(1), 41-61.

Nkopodi, N., \& Mosimege, M. (2009). Incorporating the indigenous game of morabaraba in the learning of mathematics. South African Journal of Education, 29(3), 377-392. Retrieved from: http://www.sajournalofeducation.co.za/index.php/saje

Nunes, T., Schliemann, A. D., \& Carraher, D. W. (1993). Street mathematics and school mathematics. New York, NY: Cambridge University Press. 
Pais, A. (2011). Criticism and contradictions of ethnomathematics. Educational Studies in Mathematics, 76, 209-230. doi:10.1007/s10649-010-9289-7

Paraide, P. (2005, March). The value of Indigenous mathematical knowledge in formal learning. Paper presented at the PNG Curriculum Reform Conference. Retrieved from http://www. pngcurriculumreform.ac.pg/research/evaluation.htm

Patrick, R. (1999). Not your usual maths course: Critical mathematics for adults. Higher Education Research and Development, 18(1), 85-98. doi:10.1080/0729436990180107

Powell, A. B., \& Brantlinger, A. (2008). A pluralistic view of critical mathematics. In J. F. Matos, P. Valero, \& K. Yasukawa (Eds.), Proceedings of the Fifth International Mathematics Education and Society Conference, (pp. 424-433). Lisbon, Portugal: Centro de Investigação em Educação, Universidade de Lisboa and Department of Education, Learning and Philosophy, Aalborg University. Retrieved from http://pure.ltu.se/portal/files/2376304/Proceedings_MES5.pdf

Presmeg, N. C. (1996, July). Ethnomathematics and academic mathematics: the didactic interface. Paper presented at Working Group 21, ICME 8, Seville, Spain.

Presmeg, N. C. (2002). Shifts in meaning during transitions. In G. de Abreu, A. J. Bishop, \& N. C. Presmeg (Eds.), Transitions between contexts of mathematical practices (pp. 213-228). Dordrecht, The Netherlands: Kluwer Academic Publishers.

Radford, L. (2008). The ethics of being and knowing: Towards a cultural theory of learning. In L. Radford, G. Schubring \& F. Seeger (Eds.), Semiotics in mathematics education: Epistemology, history, classroom and culture (pp. 215-234). Rotterdam: Sense Publishers.

Roberts, T. (1997). Aboriginal maths: Can we use it in school? In N. Schott \& H. Hollingworth (Eds.), Mathematics: Creating the future: Proceedings of the 16th Biennial Conference of the Australian Association of Mathematics Teachers (AAMT) (pp. 95-99). Adelaide, Australia: Australian Association of Mathematics Teachers.

Rojas, Y. M. (2010). How students learn about data distribution from addressing a problem affecting their community. In C. Reading (Ed.), Data and context in statistics education: Towards an evidence-based society: Proceedings of the Eighth International Conference on Teaching Statistics (ICOTS8), July, 2010, Ljubljana, Slovenia. Voorburg, The Netherlands: International Statistical Institute. Retrieved from http://www.stat.auckland.ac.nz/ iase/publications.php?show=icots8

Shockey, T. L. (2002). Etnomatematica de uma classe profissional: Cirurgiões cardiovasculares [Ethnomathematics a Professional Class: Cardiovascular Surgeons]. Bolema, 15(17), 1-19.

Skovsmose, O. (2004). Critical mathematics education for the future. Retrieved from http://www.icme10.dk/proceedings/pages/regular_pdf/RL_Ole_Skovsmose.pdf

Skovsmose, O. (2005). Foreground and politics of learning obstacles. For the Learning of Mathematics, 25(1), 4-10.

Stillman, G., \& Balatti, J. (2001). Contribution of ethnomathematics to mainstream mathematics classroom practices. In B. Atweh, H. Forgasz, \& B. Nebres (Eds.), Sociocultural research on mathematics education: An international perspective (pp. 313-328). Mahwah, NJ: Lawrence Erlbaum Associates.

Stocker, D., \& Wagner, D. (2007). Talking about teaching mathematics for social justice. For the Learning of Mathematics, 27(3), 17-21. Retrieved from http://www.jstor.org/stable/40248579

Sundefeld, M. L. M. M., Homse, L. C., Prieto, A. K. C., \& Rodrigues, M. A. B. (2010). The opinion of the family about the performance of the schoolchild bringing knowledge to his/her family: Statistics on prevention of mouth cancer. In C. Reading (Ed.), Data and context in statistics education: Towards an evidence-based society: Proceedings of the Eighth International Conference on Teaching Statistics (ICOTS8), July, 2010, Ljubljana, 
Slovenia. Voorburg, The Netherlands: International Statistical Institute. Retrieved from http://www.stat.auckland.ac.nz/ iase/publications.php?show=icots8

Tomlin, A. (2002). "Real life" in everyday and academic maths. In P. Valero \& O. Skovsmose (Eds.), Mathematics education and society: Proceedings of the Third International Mathematics Education and Society Conference (pp. 1-9). Copenhagen: Centre for Research in Learning Mathematics.

Valero, P. (2010). Mathematics education as a network of social practices. In V. Durand-Guerrier, S. Soury-Lavergne, \& F. Arzarello (Eds.), Proceedings of the Sixth Congress of the European Society for Research in Mathematics Education, 28th January to 1st February 2009, Lyon (France) (pp. LIV-LXXX). Institut National de Recherche Pèdagogique. Retrieved from http://www.inrp.fr/editions/editions-electroniques/cerme6/plenary-2

Vithal, R., \& Skovsmose, O. (1997). The end of innocence: A critique of "ethnomathematics." Educational Studies in Mathematics, 34, 131-158.

Wedege, T. (2010). Ethnomathematics and mathematical literacy: People knowing mathematics in society. In C. Bergsten, E. Jablonka, \& T. Wedege (Eds.), Mathematics and mathematics education: Cultural and social dimensions: Proceedings of MADIF7, The Seventh Mathematics Education Research Seminar, Stockholm, January 26-27, 2010 (pp. 31-46). Linköping, Sweden: Svensk Förening för Matematikdidaktisk Forskning (SMDF).

Wenger, E. (1998). Communities of practice : Learning, meaning, and identity. Cambridge, UK: Cambridge University Press.

Willis, S. (1998). Perspectives on social justice, disadvantage and the mathematics curriculum. In C. Keitel (Ed.), Social justice and mathematics education: Gender, class, etnicity, and the politics of schooling. Berlin, Germany: Freie Universität. 